\title{
Dance/Movement for Integrated Populations: Curriculum Design and Best Practices
}

\author{
By Joan Meggitt ${ }^{*}$ \\ Barbara Allegra Verlezzat
}

\begin{abstract}
Through this paper and the course discussed herein, the authors consider the potential for great change in the landscape of dance education at the college-level, and advocate for an inclusive model that prepares students to be more effective artists, teachers and citizens. Teaching Dance and Movement for Nontraditional Populations, a college-level undergraduate dance course that focuses on the theories, content, and pedagogical methods for teaching dance to nontraditional populations, has been developed for students in the fields of dance, education, nursing, exceptionalities and related arts and therapeutic disciplines. Nontraditional populations refers to individuals or groups that are not regularly associated with the learning, teaching, performing, and making of dance, including individuals with physical, sensory, and developmental disabilities, persons living with chronic illness, and senior adults. It is vital that dance educators offer a broader perspective on "who" can experience dance and reduce any barriers confronting those who wish to participate.
\end{abstract}

\section{Introduction}

Dance plays many roles in the life of a society and the individuals therein. It is a metaphor for life and, as such, it can reflect values, present ideas, express feelings/emotions, and render knowledge anew. A key question pursuant to this writing is: Whose metaphor is being experienced, seen and taught? The primacy of formal aesthetic values, particularly as they pertain to dance and the focus on the "hyper-able" body, ${ }^{1}$ excludes the vast majority of people from participating. This is particularly true for people with disabilities. Professors Joan Meggitt and Barbara Allegra Verlezza address the teaching of dance as an inclusive practice in Teaching Dance and Movement for Nontraditional Populations, an undergraduate college-level dance class that focuses on the theories, content, and pedagogical methods for teaching dance to nontraditional populations. Nontraditional populations include individuals with physical, sensory and developmental disabilities, persons living with chronic illness, and senior adults. The course also identifies best practices for classes that are inclusive of individuals with and without disabilities, including aligning content with nationally-recognized standards (i.e., National Core Arts Standards in Dance in the United States). Dedicated study in the realm of dance and disability is not prevalent in

\footnotetext{
*Assistant Professor of Dance, Kent State University, USA.

$\ddagger$ Associate Professor of Dance, Kent State University, USA.

1. Bailey Anderson, "Using a principle-based method to support a disability aesthetic," Journal of Dance Education 15, no. 3 (July-Sept. 2015): 88.
} 
university dance programs in the United States, most of which comprise young students without disabilities and which approach dance from an "ablist"2 perspective. Through this paper and the course discussed herein, Meggitt and Verlezza consider the potential for great change in the landscape of dance education at the college-level, and advocate for an inclusive model that prepares students to be more effective artists, teachers and citizens.

\section{Nontraditional Populations}

The term nontraditional is used in this writing to reference populations that are not regularly associated with the learning, teaching, performing and making of dance. The Americans with Disabilities Act (ADA), a civil rights law enacted in the United States in 1990, addresses equal opportunity for people with disabilities. According to the ADA, a person with a disability is defined as a person who "has a physical or mental impairment that substantially limits one or more major life activity," which includes but is not limited to, "walking, hearing, caring for oneself and working." 3 The inclusion of senior adults without disabilities does not fall under the purview of the ADA; however, they constitute a population that is also not traditionally included in the dance/movement experience despite evidence of overall benefits. Therefore, this expanded definition of nontraditional populations includes individuals whose bodily motion and/or cognitive abilities are affected by various and sometimes multiple factors for either their entire lives or for a significant portion.

Regardless of the population being served, the dance instructor must focus on movement that is appropriate for both the class as a whole and the individuals within it. This is one of the most challenging aspects for young dance artists/educators, which can be intensified when working with nontraditional populations because of the relative lack of teacher training programs at the undergraduate university level. While some dance/ movement classes may be devoted to a specific population, whether traditional or nontraditional, there are a growing number of classes which include individuals with and without disabilities. These classes will be referenced herein as integrated. Bailey Anderson proposes that a "principle-based methodology" be applied to the teaching of dance technique and choreography so that, regardless of the constituents, everyone has the opportunity to cultivate their own movement vocabulary around common movement principles; thereby shifting the dance paradigm and

2. Ann Cooper Albright, Choreographing Difference (Middletown: Wesleyan University Press, 1997), 58.

3. David Cameron, \& Trudy F. Sharp, A Sourcebook on the Americans with Disabilities Act (Columbus: Ohio Rehabilitation Services Commission, 1997), 5. 
"allow[ing] for a disability aesthetic."4 This proposition envisions a truly level playing field, or dance floor as it were. Meggitt and Verlezza utilize a multifaceted approach which includes existing dance techniques, improvisation, extant choreography, and the creation of movement based on individual design by both students and instructors.

The terms dance and technique denote established practices that train the body for physical proficiency and performance, and which encompass a wide range of styles that include social and performative structures. The term movement refers to an even broader range of physical activity that falls outside the traditions of dance and formal dance training. Improvisation refers to action in the moment, without preparation. Improvisation is also a discipline wherein the practitioner seeks to be more fully engaged in the moment, thereby acting with increased awareness and capacity. The authors utilize the term translate instead of modify. The word modify often carries pejorative undertones implying that the movement for the nontraditional student/ dancer is "less than" the movement for the traditional student/dancer. The word translate implies using a different language, one that is equally rich and creative.

For the purposes of this paper aesthetic refers to ideals of beauty, and to its value, as established by individuals, communities and society at large. Further, aesthetics is a corporeal experience. It is grounded in the body, which perceives and responds to visual as well as kinesthetic stimuli, most especially in dance. Tobin Siebers describes aesthetics as tracking "the sensations that some bodies feel in the presence of other bodies." ${ }^{\prime}$ Ann Cooper Albright utilizes the term "ablist" 6 in describing preconceptions about dance, specifically dance performance. Ablist is used here to address not only dance performance, but also the teaching of dance which, until recently, has been taught, created and performed almost exclusively by and for individuals in peak physical condition. Albright is mindful that "... while a dance performance is grounded in the physical capacities of a dancer, it is not limited by them."7

\section{Dance for Nontraditional Populations}

Dance and movement have been identified as having positive effects on brain function in that they can "affect the regulation of neurotransmitters, as suggested by Jeong et al. (2005) who reported that 'dance movement therapy

4. Anderson, "Using a principle-based method," 87-88.

5. Tobin Siebers, Disability Aesthetics (Ann Arbor: The University of Michigan Press, 2010), 1.

6. Albright, Choreographing Difference, 58.

7. Ibid. 
enhanced the concentration of serotonin, the so-called happiness hormone."'8 Lisa Heiberger et al. concluded that dancing can make participants "feel better and have a better body awareness." 9 Further, various studies of dance activity as reported by Gurley, Neuringer and Massee postulated that engaging in dance classes promoted a sense of overall "psychological well-being."10 It follows, therefore, that dance is intrinsically therapeutic; however, this is not to be confused with the specific field of dancelmovement therapy (DMT). When referencing dance for nontraditional populations, particularly people with disabilities, it is often erroneously identified as DMT. The approaches employed by Meggitt for individuals with Parkinson's disease, and by Verlezza for individuals with various disabilities, and including senior adults, are derived directly from their extensive experience as artists and educators. Their creative and pedagogical methodologies are informed by an aesthetic lens versus a therapeutic one.

Recent studies of the effects of dance for people with Parkinson's disease have yielded positive results with respect to motor functions such as gait, balance and tremor, and suggest that there may be additional positive effects on cognition and quality of life. ${ }^{11}$ Olie Westheimer et al. detail significant changes that occurred in individuals who participated consistently in Dance for Parkinson disease classes $\left(\right.$ DfPD $\left.^{\circledR}\right)$. These classes were developed in 2001 by the Mark Morris Dance Group and the Brooklyn Parkinson Group in Brooklyn, New York (USA). Utilizing a number of different rating scales established for PD features, Westheimer et al. concluded that there was significant improvement in motor symptoms. ${ }^{12}$ While quantitative measures for quality of life such as the Beck Depression Inventory (BDI) did not reach statistical significance, qualitative interviews "indicated a variety of positive outcomes to the class."13 DfPD $^{\circledR}$ has fostered a global network of dance artists and teachers who provide dance classes for people with PD. In addition, professional companies around the world are beginning to create their own dance for Parkinson's programs; for example, the English National Ballet in London, England (UK) is a DfPD ${ }^{\circledR}$ global training partner and offers its own program entitled Dance for Parkinson's.

8. Lisa Heiberger, et al., "Impact of weekly dance class on the functional mobility and on the quality of life of individuals with Parkinson's disease," Frontiers in Aging Neuroscience 3/14 (2011). DOI: 10.3389/fnagi.2011.00014.

9. Ibid.

10. Virginia Gurley, Allen Neuringer, \& Judy Massee. "Dance and sports compared: Effects on psychological well-being," The Journal of Sports Medicine and Physical Fitness 24, no. 1 (1984): 63.

11. Olie Westheimer, et al., "Dance for PD: a preliminary investigation of effects on motor function and quality of life among persons with Parkinson's disease (PD)," Journal of Neural Transmission 122, no. 9 (2015): 1265.

12. Ibid.

13. Ibid., 1269. 
Meggitt has completed multiple training workshops with $\mathrm{DfPD}^{\circledR}$ and has taught classes based on the organization's class model in Cleveland, Ohio (USA) since 2013. Her work with individuals with PD is centered on dance as a community experience, a technical discipline, and an expressive practice. She utilizes a wide variety of styles outside of her specific technical focus, the modern dance technique of Erick Hawkins, including improvisation, call and response, modern dance, ballet, jazz dance, musical theatre and folk dance. Participants place a premium on communicating with one another throughout class; consequently, dance exercises and sequences are designed to move individuals into engagement with others. This is also a principal component of the DfPD ${ }^{\circledR}$ model.

Since 1994, Verlezza and her husband, Sabatino Verlezza, have taught inclusive and programmatically accessible dance and movement classes in Ohio and New York (USA). Their diverse student populations have included individuals with various disabilities (physical, sensory, and/or developmental), children through senior adults, and dance enthusiasts through professional dancers. The majority of their teaching environments have been integrated. In training professional dancers, they utilize the technique of American modern dance pioneer, May O'Donnell. The Verlezzas, former soloists in O'Donnell's dance company, were granted "permission to 'translate' her vocabulary"14 for dancers with disabilities, including wheelchair users. "In their wheelchair training, which is extensive and inventive,"15 they have provided "a strengthening technique for those with injury or paralysis by increasing range of motion and balance, thereby giving dimension to their body expression and enriching their performance quality."16 In the Verlezzas' classes for nonprofessional dancers with disabilities, the implementation of O'Donnell vocabulary in conjunction with creative movement explorations and other dance genres and styles have generated similar results.

Dance for senior adults has been noted as ameliorating "a wide spectrum of age-related decline."17 In a study examining the effects of dance on senior adults, Kattenstroth et al. reported "beneficial effects were found for dance-related parameters such as posture and reaction time."18 In addition to the physical benefits, data demonstrated positive outcomes in "cognition, attention,

14. Marian Horosko, May O'Donnell (Gainesville: University Press of Florida, 2005), 119.

15. Ibid.

16. Ibid.

17. Jan-Christoph Kattenstroth, Tobias Kalisch, Stephan Holt, Martin Tegenthoff, \& Hubert R. Dinse, "Six months of dance intervention enhances postural, sensorimotor, and cognitive performance in elderly without affecting cardio-respiratory functions," Frontiers in Aging Neuroscience 5/5 (2013). DOI: 10.3389/fnagi. 2013.00005.

18. Ibid. 
sensorimotor performance as well as subjective well-being."19 Since 2000, the Verlezzas have taught an ongoing weekly class for senior adults with various disabilities, ages 50-91 years. Some of the participants have been dancing with the class since its inception, affording continuous observations of growth and ability by the instructors as well as the participants' community program facilitators and directors. Although the students have various developmental disabilities and levels of cognition, they have demonstrated substantial progress in all benefits previously cited by Kattenstroth et al.

\section{Course Rationale}

Dance educators have the opportunity to expand on existing notions of how and where dance happens, and who has the "right" to dance, by developing new curriculum that directly addresses dance and nontraditional populations, and which offers students appropriate field experience. Since the initiation of the ADA there has been significant growth of inclusive dance/ movement performance opportunities and employment for professional dance artists with disabilities in the United States. Dancing Wheels in Cleveland, Ohio (USA), Axis Dance Company in Oakland, California (USA), and Light Motion in Seattle, Washington (USA), as well as Candoco Company in London, England (UK) are a few examples of physically integrated professional dance companies that have been in existence for over two decades and which were founded or co-founded by individuals with disabilities. Additionally, these companies have developed educational programming including community outreach programs, ongoing community classes, residencies, master classes and/or intensive workshops for individuals with and without disabilities, and university partnerships providing classes for people with disabilities.

Inclusive programs in the arts have grown significantly, exemplified by the Department of Very Special Arts and Accessibility at the John F. Kennedy Center for the Performing Arts, an international organization focused on arts and disability. Founded in 1974 by United States Ambassador Jean Kennedy Smith, it comprises over 50 international affiliates as well as a network of nationwide associates providing educational programming in the visual, literary and performing arts, including dance, annually reaching over seven million people of all ages and abilities..$^{20}$ Private studios and community programs have developed classes, workshops and intensives for nontraditional populations and/or have integrated students into existing classes.

Integrated dance programs in the public school system in the United States

19. Ibid, 14 .

20. VSA The International Organization on Arts and Disability, The John F. Kennedy Center for the Performing Arts, 1990-2016. 
have been implemented, for example, through partnerships with professional inclusive dance companies, such as Karen Peterson and Dancers. This Floridabased "mixed abilities" company established in 1990 holds fifteen-week residencies in 24 middle/high schools throughout the Miami-Dade area, teaching dance to students with "autism, learning disabilities, and visual, physical, language and emotional impairments."21 In February 2016, Dance/NYC released a research report, Disability. Dance. Artistry., addressing dance instruction for disabled students in public schools. ${ }^{22}$ Paul L. King, Executive Director of the Office of Arts and Special Projects for the New York City Department of Education, cites the report as "a call to action for a future where artists with disabilities flourish."23

University dance programs have answered this call; however, further development is necessary. There is a need for more opportunities for students to engage in diverse, inclusive learning environments and for teacher training specific to both nontraditional and integrated class settings. This can be accomplished, in part, through the development of dedicated dance courses that address pedagogical approaches for nontraditional populations from an artistic viewpoint. For example, Eastern Michigan University provides undergraduate course offerings in dance and disability specifically for pre-DMT students. ${ }^{24}$ Outside of DMT and dance education programs, it is uncommon to find dance and disability course offerings. In Teaching Dance and Movement for Nontraditional Populations, Meggitt and Verlezza place the focus firmly on dance as an art form.

It is essential that the learning environment promotes equal ground for all participants, whether stand-up, sit-down, young, old, novice or veteran. ${ }^{25}$ Albright suggests looking at ability as a "continuum."26 By expanding the ability continuum beyond an "either/or situation," 27 educators cultivate an environment wherein there is room for everyone to participate in the physical, conceptual, emotional and sensorial experiences that dance offers.

Years of working with college interns/demonstrators in the authors' ongoing

21. Karen Peterson, "Mixed Ability Dance: Helping Students with Special Needs Grow and Learn," Edutopia, George Lucas Education Foundation, last modified April 22, 2013, accessed April 17, 2016, goo.gl/4XKQpl.

22. Dance/NYC, Disability. Dance. Artistry, last modified July 8, 2015, accessed April 16, 2016, goo.gl/ZRw0RW.

23. Ibid.

24. Catalogue-Dance Major, School of Music and Dance, Eastern Michigan University, accessed April 23, 2016. goo.gl/aDR6CE.

25. Stand-up dancers/movers are identified as people who stand on their feet, including individuals who use assistive devices such as canes, walkers, crutches, etc. to facilitate weight-bearing and locomotion. Sit-down dancers/movers are identified as people who use wheelchairs and/or stationary chairs, benches, etc.

26. Albright, Choreographing Difference, 87.

27. Ibid. 
community dance programs and annual intensives in Ohio and New York have demonstrated that there are a significant number of university students from various disciplines who are interested and invested in working with nontraditional populations. These students have subsequently pursued careers in inclusive dance performance/choreography, dance education for nontraditional populations in public and private settings, and DMT. In addition, conference presentations, master classes and workshops led by the authors have garnered interest from university students and dance and education professionals across the United States. The predominant guiding principles are to ensure equity in the classroom, expand the definition of "beauty" as it applies to the aesthetics of the body and of dance, translate the movement "vocabulary" as defined by the formal tenets of various dance genres, and approach all aspects of the work from an artistic point of view versus a therapeutic perspective.

\section{Course Design}

Teaching Dance and Movement for Nontraditional Populations is designed to function within a pre-existing university undergraduate dance curriculum that includes a BFA in Dance Performance, a BA in Dance Studies, and a minor in Dance. The established curriculum includes two dance education courses that address teaching dance to children, and teaching dance to students from middle school through adulthood in both public and private settings, Dance for Children and Methods and Materials respectively. While Teaching Dance and Movement for Nontraditional Populations augments these dance education offerings, it also informs studies in dance technique, composition, history, dance appreciation, kinesiology and dance mechanics, and career seminars in dance. In addition, it complements inquiry in the fields of education, nursing, exceptionalities and related arts and therapeutic disciplines.

\section{Course Objectives}

There are four primary objectives set forth in Teaching Dance and Movement for Nontraditional Populations. These objectives are intended to provide a broad base with respect to nontraditional populations, while also recognizing the uniqueness of specific populations. Professor Meggitt's work with individuals with Parkinson's disease (PD), and Professor Verlezza's work with individuals with disabilities, and senior adults, will inform said specificity. 
1. The course will provide a base of knowledge and skills related to developing a dance and movement class for nontraditional populations.

This refers to a class that is constituted solely of individuals from one or more nontraditional populations.

2. The course will provide a base of knowledge and skills related to developing a dance and movement class in an inclusive environment including participants with and without disabilities and/or movement disorders.

This pertains to a class that recognizes a continuum of abilities and works to mediate a demonstrative teaching model. ${ }^{28}$

3. The course will provide a base of knowledge pertaining to accessibility as defined by the 1990 Americans with Disabilities Act (ADA) and its application to a dance environment.

The ADA specifies accommodations for individuals with disabilities to ensure equal opportunity. Meggitt and Verlezza will utilize this legislation as a point of departure in addressing equal opportunity in the dance studio.

4. The course will provide opportunities for students to observe, demonstrate, assist, and teach dance and movement to specific nontraditional populations.

This is, perhaps, the most important aspect of the course. Involving students in a larger realm that challenges assumptions about dance and the body is key to effective application of all the knowledge and skills addressed in the three previous objectives. It engages students in the greater community and is instructive in guiding the students to recognize potential partners for developing dance programs for nontraditional populations. These partners include hospitals, rehabilitation centers, schools, senior adult facilities, retirement homes/centers, populationspecific organization/centers, social services and local government community programs, recreation/community centers, health clubs, private dance/movement studios and professional dance companies.

\section{Course Learning Outcomes and Methodology}

The learning outcomes for Teaching Dance and Movement for Nontraditional Populations are manifold. They address numerous aspects of teaching dance at large; they speak to an understanding of a variety of nontraditional populations and how to serve them equally through dance and movement; and they ask students to broaden their perspectives and skills. Methodology and best practices are laid out for each learning outcome.

28. Anderson, "Using a principle-based method," 89. 
- Articulate an understanding of characteristics of disabilities, specific illnesses, and advanced age that affect movement and cognition.

Lecture presentations and readings will address a variety of disabilities and illnesses, as well as advanced age, and the manner in which movement and cognition are affected. While there may be shared concerns, no two populations are the same, and there is great variability within any single cohort. For example, every case of Parkinson's disease is different. There are shared experiences, but the progress of the disease is different from person to person and is reliant on a vast multitude of factors. Preparing students to be both knowledgeable and flexible in their approaches is an important part of developing their methodology.

- Identify fundamental elements of a basic dance and movement class and the primary skills and concepts that are central to dance and movement.

Firsthand experience in a variety of dance/movement classes, group discussions, and written reflection will be the central methodology for this learning outcome. The instructors will provide a comprehensive module on dance technique that examines syllabi and rubrics from a variety of dance/movement classes. The instructors will each offer a class in their respective techniques, and students will be required to observe additional dance classes. Guest teachers with expertise in world dance/movement forms will teach master classes as well.

- Establish appropriate goals for a variety of populations.

Bearing in mind Learning Outcomes 7.1 and 7.2, inquiry into appropriate goals will include in-class discussion, individual and group exploration in the dance studio, and participation in classes for students from nontraditional populations. A random sampling of dance/movement classes should yield a set of common practices which effectively address movement principles at large. Students will then explore the specific approaches necessary in addressing distinct nontraditional populations.

- Demonstrate an understanding of movement translation and accommodation methods of inclusion.

This is a practical component of the course wherein instructors work with the students in the dance studio to learn movement fundamentals and established practices for translating movement and applying these across a variety of dance techniques and styles. For example, the class will explore 
different modes of locomotion, including the use of various types of wheelchairs (power, traditional, and specially-designed chairs used by athletes and professional dancers). Through a series of movement combinations, the participants will explore basic wheelchair technique and vocabulary, such as opposition turns, figure- 8 turns, the translation of lateral movement through space for a wheelchair dancer, and advanced technical work including frontend/"wheelie" work, complex turns, and balance work such as on one wheel. Another example includes the exploration of walking patterns for students with $\mathrm{PD}$ and cerebral palsy $(\mathrm{CP})$ to maintain stability while moving through space.

- Apply movement translation and accommodation methods in demonstrating for and teaching a dance and movement class.

This is a practical component that takes place in the dance studio as well as in the field. In the studio, students will work with the instructors and one another in a mock class situation. In the field, the students will work directly with nontraditional populations and will, under the guidance of the instructors, devise and demonstrate movement translations for the class. In addition, the appropriate use of a demonstrative teaching model will be addressed. Many dance/movement classes rely on shape-based demonstration and students' visual acuity and ability to replicate the instructor's form. For nontraditional populations this is not always possible, nor is it necessarily desirable. In addition to the dance/movement fundamentals and principles referenced in Learning Outcomes 7.2 and 7.3, student teachers will identify and work with other key elements, such as dynamics, character, meter/rhythm, relationship, intention and overall demeanor.

- Develop exercises and phrase work that meet the goals of a dance and movement class for specific populations.

There are a broad range of exercises and phrases that can meet individual goals. Some classes are purely recreational while others may be centered on technical improvement and preparation for formal performance. The students' task then, is twofold: identifying the overall purpose of the class, and meeting the needs of the participants as indicated by the degree to which their bodily motion and/or cognitive abilities are affected. In addition to using formal dance technique/movement, for instance the traditional ballet arm positions/port de bras, there are a great variety of methods through which teachers/students can make the dance more accessible. Some examples include the use of American Sign Language (ASL), guided imagery, props/costumes, the expansion of taskoriented movement, improvisation, contact improvisation, composition, partnering and storytelling. 
- Establish practices for evaluating individual progress of nontraditional class participants.

Students will develop lesson plans and rubrics that address a number of different population-specific dance/movement classes. Instructors will guide students in discerning best practices for dance/movement at large and for nontraditional populations. This will also entail aligning content with recognized dance standards such as National Core Arts Standards in Dance in the United States (pre-K through 12).

- Build collaborative teaching skills.

The bulk of class projects will be team-based. Many teaching models for nontraditional populations recommend either multiple demonstrators per single instructor or two instructors with additional demonstrators as needed. This is to better facilitate dance/movement translation within inclusive settings such as classes for participants with and without disabilities. For example, a class that includes both stand-up and sit-down participants may need demonstration of movement translations between the lower and upper body.

- Differentiate between dance as an expressive art and dance a therapeutic practice.

Through lecture, discussion and writing students will learn what separates dance from related fields, such as DMT and physical, recreational and occupational therapies.

\section{Conclusion}

As the scope of society's awareness increases to embrace diversity in all facets of life, the dance community has a shared responsibility in this endeavor. Dance artists and educators must also be responsive to ongoing developments in the field and provide comprehensive training to students. University curriculum design can embrace a more inclusive model that recognizes a continuum of abilities. Course work can, in turn, provide young dance educators and artists with methodology that mediates the potential exclusivity of dance. Educators have the opportunity to inspire and motivate students to appreciate, participate in, and contribute to the arts in an inclusive, intelligent and thoughtful manner. The arts have always inspired humanity to think, to interpret, and to stretch. It is time to broaden the parameters of who is "allowed" to be the artist/teacher that inspires the audience/student. Historically, individuals with disabilities have been assigned the role of observer over actor. It is essential that the dance 
community engage the potential artists in this population and ensure that anyone who has the passion, the drive and the talent has equal opportunity to become a powerful contributor, leader and role-model.

In truth, the only equality in any aspect of life is to be given the opportunity to try, even if it is only to discover that one does not like something. Therein lies great freedom to forge ahead to new perspectives and pursuits. As educators, community members and citizens at large, dance artists have a share in the responsibility to afford these opportunities to all who wish to try, and to guide the student, from enthusiast to professional, with appropriate educational tools. By proceeding in this manner, everyone has agency in the teaching, learning and creation of dance.

\section{Acknowledgements}

The authors extend sincere thanks to Kent State University and the School of Theatre and Dance for supporting this research; and to Prof. Kimberly Karpanty, Brian Meggitt and Sabatino Verlezza.

\section{Bibliography}

Anderson, Bailey. "Using a principle-based method to support a disability aesthetic." Journal of Dance Education 15, no. 3 (July-Sept. 2015): 87-90.

Albright, Ann Cooper. Choreographing Difference. Middletown: Wesleyan University Press, 1997.

Cameron, David, \& Sharp, Trudy F. A Sourcebook on the Americans with Disabilities Act. Columbus: Ohio Rehabilitation Services Commission, 1997.

Siebers, Tobin. Disability Aesthetics. Ann Arbor: The University of Michigan Press, 2010.

Heiberger, Lisa, Maurer, Christoph, Amtage, Florian, Mendez-Balbuena, Ignacio, Schulte-Mönting, Jürgen, Hepp-Reymond, Marie-Claude, \& Kristeva, Rumyana. "Impact of weekly dance class on the functional mobility and on the quality of life of individuals with Parkinson's disease." Frontiers in Aging Neuroscience 3/14 (2011). DOI: 10.3389/fnagi. 2011.00014.

Gurley, Virginia, Neuringer, Allen, \& Massee, Judy. "Dance and sports compared: Effects on psychological well-being." The Journal of Sports Medicine and Physical Fitness 24, no. 1 (1984): 58-68.

Westheimer, Olie, McRae, Cynthia, Henchcliffe, Claire, Fesharaki, Arman, Glazman, Sofya, Ene, Heather, \& Bodis-Wollner, Ivan. "Dance for PD: a preliminary investigation of effects on motor function and quality of life 
among persons with Parkinson's disease (PD)." Journal of Neural Transmission 122, no. 9 (2015): 1263-1270.

Horosko, Marian. May O'Donnell. Gainesville: University Press of Florida, 2005.

Kattenstroth, Jan-Christoph, Kalisch, Tobias, Holt, Stephan, Tegenthoff, Martin, \& Dinse, Hubert R. "Six months of dance intervention enhances postural, sensorimotor, and cognitive performance in elderly without affecting cardio-respiratory functions." Frontiers in Aging Neuroscience 5/5 (2013). DOI: 10.3389/fnagi.2013.00005.

VSA The International Organization on Arts and Disability. The John F. Kennedy Center for the Performing Arts. 1990-2016.

Peterson, Karen. "Mixed Ability Dance: Helping Students with Special Needs Grow and Learn." Edutopia. George Lucas Education Foundation. Last modified April 22, 2013. Acccessed April 17, 2016. goo.gl/4XKQpl.

Dance/NYC. Disability. Dance. Artistry. Last modified July 8, 2015. Accessed April 16, 2016. goo.gl/ZRw0RW.

Catalogue-Dance Major. School of Music and Dance, Eastern Michigan University. Accessed April 23, 2016. goo.gl/aDR6CE. 